\section{Endoscopic Removal of Retained Surgical Gauze}

We present here two cases of retained surgical gauze successfully removed endoscopically. The first case was a 43 -year-old woman who presented with persistent vomiting following cholecystectomy, which had been performed seven months before. A whitish structure projecting from the anterior wall of the duodenal bulb was removed endoscopically, and was found to be a piece of surgical gauze. There was a stoma in the anterior bulb wall after gauze removal, through which dye was injected, revealing a paraduodenal cavity, but without leakage into the peritoneal cavity. Endoscopic retrograde cholangiopancreatography revealed no communication between the cavity and the bile duct (Figure 1). Oral feeding was withheld for 24 hours, and the patient was discharged in a completely normal condition after three days.

The second case was a 47-year-old woman who presented with lower abdominal pain, tenesmus, and bleeding per rectum. She had undergone a hysterectomy six months previously. Colonoscopy revealed a whitish structure projecting into the sigmoid colon (Figure 2), which was removed in fragments and found to be a piece of surgical gauze. During six months of follow-up, there was a gradual disappearance of symptoms, and colonoscopy revealed narrowing of a short segment of the sigmoid colon.

In the literature, the reported incidence of surgical gauze left behind has varied between 1 in 100 and 1 in 3000 procedures (1). In our two cases, the gauze presented through chronic fistulation to the gastrointestinal tract following an inflammatory foreign-body reaction around the gauze (2).

M. Naga, E. El-Mootasem, E. El-Nezamy, M. Said

Department of Internal Medicine, Kasr El-Ani Hospital, University of Cairo, Cairo, Egypt

\section{References}

1. Chorvat G, Kahn J, Gamelo G et al. I'evolution des corps etrangers textiles oubliés dans l'abdomen. Ann Chir 1976; 30: 643-649.

2. Sturdy JH, Baird RM, Gerein AN: Surgical sponges; a case of granuloma and adhesion formation. Ann Surg 1967; 165: 128-134.

\section{Corresponding Author}

M. Naga, M.D., Department of Internal Medicine, Kasr El-Ani Hospital, University of Cairo, Cairo, Egypt

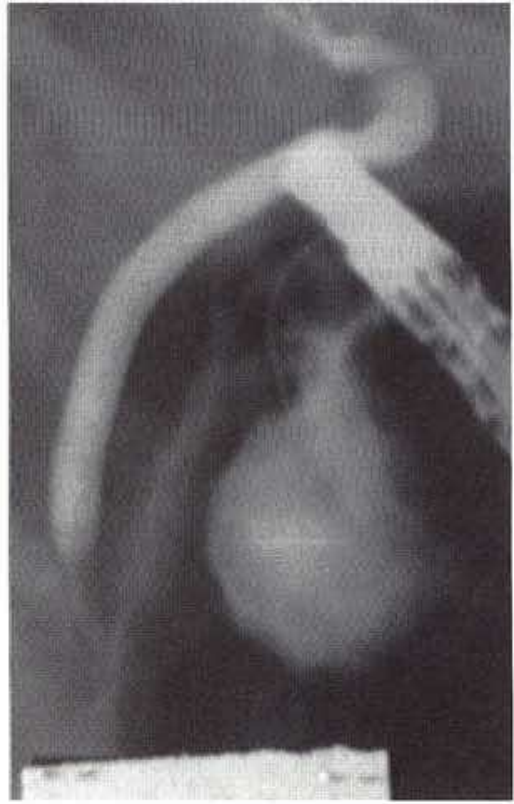

Figure 1:

A catheter was passed into the paraduodenal diverticulum, and dye was injected no leakage is seen. The common bile duct is seen beside the cavity.

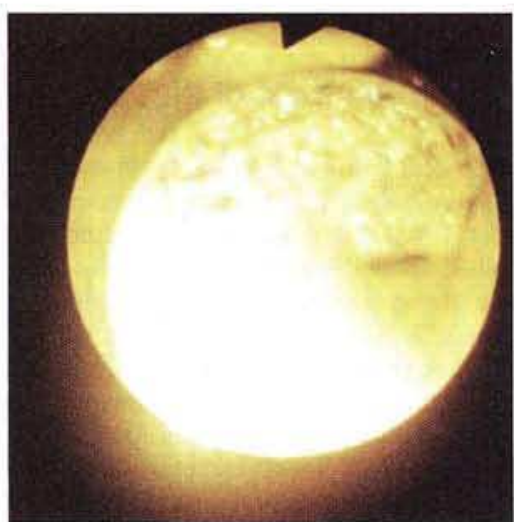

Figure 2:

Surgical gauze projecting through the colonic wall. 